\title{
Materials Science Expertise Rallied to Assist with Fukushima
}

\section{Lynne Robinson}

Even for a nation where earthquake preparedness is a way of life, the 9.0-magnitude temblor and resulting tsunami that devastated northern Japan on March 11 strained the boundaries of comprehension. While struggling to recover from the impact of thousands dead, tens of thousands displaced, and billions of dollars in damage to property and infrastructure, Japan has also faced the most serious nuclear emergency since the explosion and fire at the Chernobyl Nuclear Power Plant in 1986 (Figure 1).

Unlike Chernobyl, the events that continue to unfold at the Fukushima Daiichi Nuclear Power Station have been recorded for the world to see and study, thanks to the internet and other cuttingedge communication technologies. This gave nuclear industry experts from throughout the world unprecedented access to information within the first few days of the crisis. The U.S. Department of Energy (DOE), for instance, marshaled a small army of staff, national laboratory experts, university researchers, and industry consultants to collect and interpret available data and develop preliminary assessments. After correlating their findings with similar studies conducted by the nuclear industry and U.S. Nuclear Regulatory Commission, these and other analyses were transmitted to Japan through the U.S. Embassy to offer insights and support as the situation progressed.

Jeremy Busby, senior research scientist, Oak Ridge National Laboratory, was one of the experts tapped to participate in this process. He and the other materials science professionals working on the project quickly found that Fukushima posed a truly unique set of issues. Most notably, Japanese officials decided to use seawater to cool the reactor core to contend with the plant's emergency generators being destroyed when the 15 -meter tsunami crashed over its seawall, while also being cut off from reserve power and fresh water due to the devastation of the surrounding infrastructure.

"Injecting seawater into the reactor cores was an essential part of managing the events at Fukushima as they progressed. However, this is the first time that such large volumes of seawater were introduced into a reactor," said Busby. "The impact on material performance is outside normal experience."

Busby was part of a national team assembled to assess corrosion issues, while also examining potential strategies to reduce corrosion rates in the long-term stabilization of the plant. "The introduction of seawater creates some significant corrosion challenges," he said. "Normal water in a boiling water reactor is very controlled with limited impurities. Seawater is filled with many different compounds and impurities, including calcium, magnesium, and sodium. Perhaps most significantly, it contains chloride ions that can really change how materials perform.

"For example, stainless steel com-

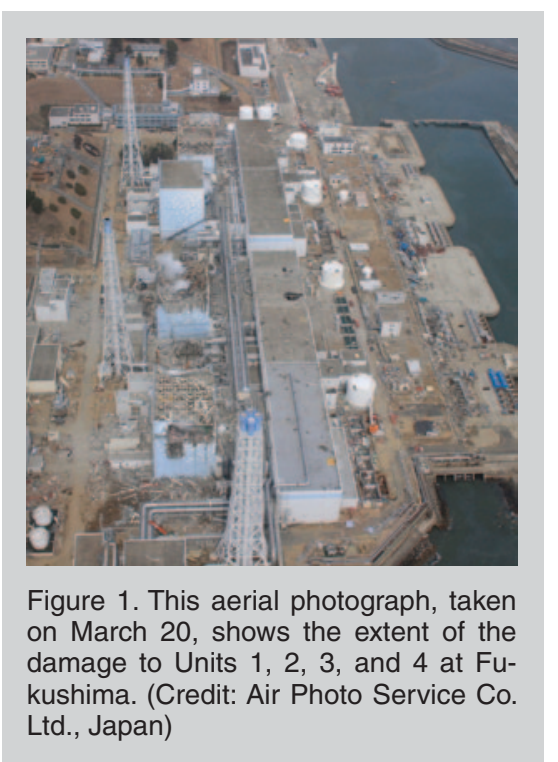

ponents inside the reactor may see increased susceptibility to stress-corrosion cracking in chloride-bearing solutions. Pitting may be an issue, and for the reactor pressure vessel, general corrosion could increase."

While seawater had only been used for about a week until the fresh water supply was restored, Busby said that these degradation issues will need to be monitored and observed for years in the management and remediation of the Fukushima site.

Busby further noted that he and the other corrosion experts supporting the DOE's analysis efforts were charged with developing a list of strategies to minimize the corrosion over the longterm, and then prioritizing them based on practical application. "Some ideas were a little more abstract, such as providing sacrificial electrodes to minimize corrosion to key components," said Busby. "Other ideas were more standard practices. These included reducing the water temperature, reducing dissolved oxygen in the water being introduced, managing the $\mathrm{pH}$, and removing salts from the water." Busby said these options were shared with the Japanese government, with many of them currently being employed.

"It will take some time to fully understand the progression of events at each of the units at Fukushima and identify sound lessons-learned," said Busby. "It will also take some time to assess the materials performance and corrosion degradation issues in each of the units. However, I'm hopeful that the analysis and information compiled by the DOE will be of some value to the Japanese during the recovery and management of the Fukushima site and make the job a little easier."

Lynne Robinson is a news and feature writer for TMS. 